\title{
Links between multidecadal and interdecadal climatic oscillations in the North Atlantic and regional climate variability of northern France and England since the 17th century
}

\author{
Bastien Dieppois, ${ }^{1}$ Alain Durand, ${ }^{1}$ Matthieu Fournier, ${ }^{1}$ and Nicolas Massei ${ }^{1}$ \\ Received 19 November 2012; revised 5 April 2013; accepted 5 April 2013; published 29 May 2013.
}

[1] Knowledge of the variability of climate in the past is essential for understanding current climatic changes. Therefore, we investigated two temperature indices and seven rainfall time series of northwestern Europe since the 17th century. Trends and multidecadal to interdecadal variability are similar in England and northern France for temperature, whereas a strong regional contrast is evident between the two regions for rainfall. Multidecadal and interdecadal variability displays several periods of enhanced amplitude for both temperature and rainfall that may be related to large-scale climate control. On these scales, temperatures in both England and France display phase opposition with the Atlantic Multidecadal Oscillation (AMO) before 1800, while they are in-phase afterward, as determined by wavelet coherence. On the other hand, the relationships between temperature and the North Atlantic Oscillation (NAO) are weak across multidecadal and interdecadal scales for the whole period under study. For rainfall, coherence with the AMO is observed for scales at around 30-60 years, whereas coherence with the NAO is detected on 50-80 year scales and interdecadal 16-23 year scales. However, relationships between rainfall variability and North Atlantic climate indices are highly contrasted depending on the region considered. Finally, the results of a mixed spectral/empirical orthogonal function analysis of mean sea level pressure on these co-oscillation time scales highlight not only NAO regimes but also other patterns, explaining a nonnegligible amount of variance during certain time periods.

Citation: Dieppois, B., A. Durand, M. Fournier, and N. Massei (2013) Links between multidecadal and interdecadal climatic oscillations in the North Atlantic and regional climate variability of northern France and England since the 17th century, J. Geophys. Res. Atmos., 118, 4359-4372, doi: 10.1002/jgrd.50392.

\section{Introduction}

[2] In the context of climatic and environmental changes, knowledge on the variability of climate in the past is fundamental for comprehension of the mechanisms at play. These changes are observed in hydrologically relevant variables and affect human activities as well as ecosystems. In this sense, studies included in some reports of the Intergovernmental Panel on Climate Change (IPCC) show an increase in annual rainfall and temperature since the beginning of the 20th century in northwestern Europe [Christensen et al., 2007]. Moreover, according to IPCC projections [Christensen et al., 2007] and to the European Action Towards Comprehensive Climate Impacts and Adaptations Assessment (ACACIA) project [Parry, 2000], this increase is expected

\footnotetext{
${ }^{1}$ Laboratoire Morphodynamique Continentale et Côtière (M2C), UMR 6143, CNRS/Université de Rouen, Mont-Saint Agnan, France.

Corresponding author: B. Dieppois, Laboratoire Morphodynamique Continentale et Côtière (M2C), UMR 6143, CNRS/Université de Rouen, FED 4116 SCALE, Place Emile Blondel, FR-76821 Mont-Saint Agnan, France. (bastien.dieppois@univ-rouen.fr)

C2013. American Geophysical Union. All Rights Reserved. 2169-897X/13/10.1002/jgrd.50392
}

to continue during the 21 st century but will be marked by significant variations on the regional scale. In general, the climate changes prior to the Industrial Revolution in the 18th century can be explained by natural causes, such as changes in solar activity, volcanic eruptions, and natural changes in greenhouse gas concentrations [Jansen et al., 2007]. The recent and future trends, however, cannot be explained by natural causes alone [Jansen et al., 2007], but the anthropogenic effects are obscured by the presence of decadal natural climate variability. Thus, based on longterm climatic records back to the preindustrial period, we propose a statistical study of time evolutions of the multidecadal to interdecadal influence of North Atlantic climatic oscillations on observed climatic variations of temperature and rainfall in northwestern Europe (England and northern France).

[3] The spectral signature of the global natural climate includes the multidecadal oscillation (65-70 or 50-88 years on the North Atlantic) [Schelsinger and Ramankutty, 1994] and the interdecadal oscillation (15-35 years) [Mann et al., 1995]. On the Atlantic basin, the multidecadal variability of the sea surface temperatures (SSTs) refers to the Atlantic Multidecadal Oscillation (AMO) [Enfield et al., 2001; Knight et al., 2006]. In addition, the North Atlantic 
Oscillation (NAO) exhibits strong variability without presenting, contrary to the AMO, any characteristic time scales; however, it can be noted that the end of the 20th century was dominated by decadal fluctuations [Hurrell, 1995; Wanner et al., 2001; Massei et al., 2007]. Nevertheless, although the present study does not aim to explore such interactions, we will note that the multidecadal variability could be internal to the ocean-atmosphere interactions [Schelsinger and Ramankutty, 1994; Higuchi et al., 1999; Enfield et al., 2001].

[4] According to earlier studies, the AMO describes the SST variability of the North Atlantic presenting cold phases (1900s, 1920s, and 1960s-1980s) and warm periods (1930s1950s and currently) [Enfield et al., 2001] related to the climatic variations throughout the globe [Knight et al., 2006]. In particular, the AMO appears to be related to the cyclonic activity of the North Atlantic [Goldenberg et al., 2001] as well as the summer climate in North America and Europe [Enfield et al., 2001; Sutton and Hodson, 2005]. Moreover, the AMO is related to variability in the oceanic thermohaline circulation, notably the Atlantic Meridional Overturning Circulation [Zhang et al., 2007].

[5] The NAO, which is generally stronger during the winter months, refers to a redistribution of atmospheric mass between the Arctic and the subtropical Atlantic and swings from one phase to another, producing large changes in the mean wind speed, direction, and the heat and moisture transport between the Atlantic and the neighboring continent [Hurrell, 1995]. This oscillation is described as the main fluctuation of climate conditions over Europe [Hurrell, 1995]: in the positive phase, wetter and warmer winter conditions are produced in Northern Europe, Scandinavia, and the East Coast.

[6] Most of the multidecadal and interdecadal scale studies have investigated paleoclimatic reconstructions in order to separate possible anthropogenic climate change from natural climate variability [e.g., Schelsinger and Ramankutty, 1994; Mann et al., 1995; Cook et al., 1998; Luterbacher et al., 1999, 2002, 2004]. Moreover, substantial studies based on observed measurements focused on the last century, notably the last 50 years, which limits the study of multidecadal relationships. Out of these few decades, the AMO only achieved two complete cycles [Enfield et al., 2001; Knight et al., 2006]. On the other hand, the study of the relationships between NAO, temperature, and rainfall also presents several problems related to the number and the complexity of the physical mechanisms involved [Kingston et al., 2006, 2007], the degree of temporal nonstationarity [Massei et al., 2007, 2010; Gamiz-Fortis et al., 2008], as well as the seasonal [Hurrell and Deser, 2009] to interannual [Hilmer and Jung, 2000; Jung et al., 2003] fluctuations in the mean position of NAO poles.

[7] In this paper, we analyze the relationships between North Atlantic climate oscillations and the observed regional climate of northern France and England over multidecadal and interdecadal time scales back to the preindustrial period. In this aim, we use the AMO and NAO indices as well as temperature and rainfall time series of selected weather stations. We also investigate the spatiotemporal variations of circulation patterns (SLP, sea level pressure) in terms of multidecadal to interdecadal variability to ensure a more accurate characterization of the links between the North
Atlantic SLP pattern and regional climate time series. More specifically, based on spectral analyses of nonstationary processes, we address the issue of the changing characteristics of such relationships over an extended time period marked by an upward trend of anthropogenic forcing, i.e., since the Little Ice Age up to the Industrial Age.

\section{Data}

\subsection{Temperature and Rainfall Data}

[8] The monthly rainfall amounts used for the study originate from the NOAA/NCDC Global Historical Climate Network database [Peterson and Vose, 1997]. Seven time series were selected from various weather stations (Figure 1): Mansfield (1807-1989), Podehole (1726-1994), Oxford (1767-2011), Kew Garden (1697-1999); Lille (17842003), Paris (1770-2004), and Rouen (1845-2008). We also had available two monthly homogenized indices of mean temperatures in Paris [Rousseau, 2009] and England (Central England Temperature, CET) [Manley, 1974]. These time series of variable lengths covered more than 150 years, which allowed us to satisfactorily investigate multidecadal and interdecadal variability.

[9] In addition, modifications of measurement conditions at one rain gauge station (rain gauge station displaced, measurement instruments replaced, etc.) can introduce artificial shifts in the data that do not reflect real climate variations. The temperature data (Paris and CET indices) used for this study were already subjected to a homogenization procedure, contrary to the rainfall time series. Although correction factors had been applied to these rainfall time series [Tabony, 1980, 1981], some residual inhomogeneity might remain. The homogeneity of rainfall time series in England and northern France, respectively, was assessed by comparison with the England and Wales homogenized indices [ $\mathrm{Al}$ exander and Jones, 2001] and the northern France regional average (latitude: $46.5^{\circ} \mathrm{N}-50^{\circ} \mathrm{N}$; longitude: $1^{\circ} \mathrm{E}-4^{\circ} \mathrm{E}$ ) from the CRU TS 3.10.1 data set [Mitchell and Jones, 2005]. Homogeneity was assessed using the following approach: (i) a segmentation procedure shows that changes in means of

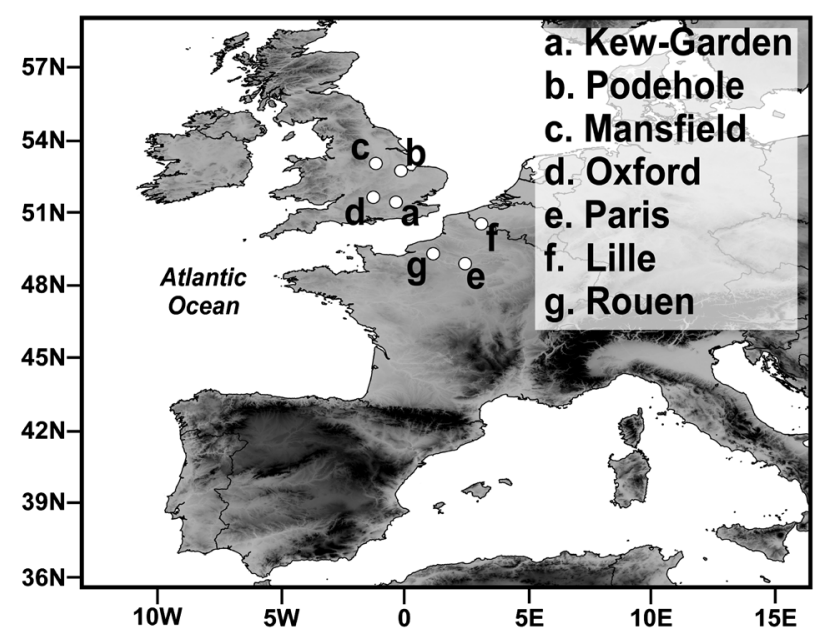

Figure 1. Localization of the rain gauge series studied in (a-d) England (Kew Garden, Podehole, Mansfield, and Oxford) and (e-g) northern France (Paris, Lille, and Rouen). 
homogenized rainfall indices are generally synchronous at the neighboring gauges; (ii) for the French rain gauge stations, any association between changes in mean and station displacements are rejected from a detailed study of the meteorological archives (source: Météo-France); (iii) quantilequantile comparisons reveal small deviations of the normal distribution between homogenized and raw data; and (iv) linear correlations between homogenized and raw data are always significant at the $95 \%$ confidence limit and ranged from 0.74 to 0.87 . Thus, as already stated in few earlier studies [e.g., Thompson, 1999; Slonosky, 2002; Thompson and Clark, 2008], all these time series can be considered homogeneous.

\subsection{Climate Indices}

[10] To study the relationship between temperature and rainfall with the Atlantic's climate variability, the AMO and NAO indices were selected. However, the AMO and NAO indices cannot be calculated based on the observed data before 1870 and 1821, respectively. Therefore, the robustness of the multidecadal and interdecadal relationships was addressed using the multisecular reconstructions of the $\mathrm{NAO}$ and AMO indices (NAOr and AMOr) of Luterbacher et al. [1999] and Gray et al. [2004]. The corresponding data sets are freely available on the NOAA Paleoclimatology Program website (www.ncdc.noaa.gov/paleo/recons.html). The NAOr index uses a combination of observed data, proxy data, and document archives to reconstruct the NAO until 1659 A.D. On the basis of comparisons between different reconstructed NAO indices and the calculated NAO, Schmutz et al. [2000] estimated that the reconstruction of the NAO index by Luterbacher et al. [1999] was the most coherent. Based on tree ring analyses, the AMOr index is an annual reconstruction since 1567 A.D., statistically verified based on proxy data in North America, western Europe, Scandinavia, and the Middle East [Gray et al., 2004].

\subsection{SLP Data}

[11] The mean sea level pressure (SLP; $5^{\circ}$ latitude $\times 5$ longitude) fields are a regional selection $\left(25^{\circ} \mathrm{N}-88^{\circ} \mathrm{N}\right.$, $90^{\circ} \mathrm{W}-40^{\circ} \mathrm{E}$ ) from the HadSLP2 $\mathrm{r}$ data set compiled by the Met Office Hadley Centre. This data set was created from in situ ocean measurements (International Comprehensive Ocean-Atmosphere Data Set) and 2228 continental stations between 1850 and 2004. These land and ocean observations were combined and then reconstructed using statistical methods, making it possible to obtain a stable reconstruction [Allan and Ansell, 2006]. Next, the HadSLP2r database was created by extending the HadSLP2 database up to 2005 and by adjusting the climatological means using the National Centers for Environmental Prediction/National Center for Atmospheric Research reanalyses.

\section{Methodology}

\subsection{Rainfall Analyses}

[12] In section 4.1, serial correlations in the annual time series were first assessed by computing autocorrelation functions, and subsequently, a monotonic trend was investigated using the Mann-Kendall trend test [Mann, 1945; Kendall, 1948]. This test is performed on the annual time series of different lengths and to a common data period (since 1845).
Thus, the trend intensity and the statistical significance are given by the Kendall rank correlation coefficient (i.e., the Kendall's tau statistics) and the two-sided $p$ value, respectively. Next, all time series were standardized (i.e., values are then expressed as $Z$ scores) in order to investigate the time evolutions of annual rainfall and temperature by adjusting the different degrees of smoothing of a locally weighted nonparametric polynomial regression (LOESS). This method has already been successfully applied in the study of climatic variations [Cleveland and Devlin, 1988]. Two smoothing windows were used: (i) one equal to the length of the shortest time series studied (164 years) for assessing the general trend of the time series (solid line in Figure 2) and (ii) an 50 year smoothing window for evaluating the multidecadal temperature and rainfall trend in England and northern France (dashed line in Figure 2).

[13] So that the identification of the temperature and rainfall variability scales are not affected by the length of the time series observed and by nonstationarity, the continuous wavelet transform (CWT) was applied to the three longest time series (temperature: CET index; rainfall: Kew Garden and Paris; section 4.2). Briefly, the convolution of the climatic signals by a sum of wavelets of finite length (nonorthogonal) is used to produce a univariate spectrum of sufficient power to identify the spectral components corresponding to the dominant modes of climate variability over time, based on a time/scale reference (Figure 3). The detailed explanations of the CWT and its applications to climate signals are now widely documented in the literature [Torrence and Compo, 1998; Labat, 2005; Massei et al., 2007, 2010]. The statistical significance of the spectral components was assessed using the pointwise test described by Torrence and Compo [1998] and Maraun [2006]. Then, the ranges of variability detected by the CWT were reconstructed using inverse Fourier transform applied to all time series throughout the year (Figure 4). In this way, the power of the annual dominant modes of variability can be compared over time on an orthogonal basis.

\subsection{Analysis of the Relationship Between the Regional Climate in Northern France and England and North Atlantic Signals}

[14] In section 5.1.2, the time/frequency stability of the relationship between temperature/rainfall and the climate indices is analyzed using coherence and wavelet phase. This approach has already been successfully applied in hydroclimatology [Torrence and Webster, 1999; Maraun, 2006]. Wavelet coherence evaluates the level of linear correlation between two time series $x(t)$ and $y(t)$ at a time $t i$ on a variability scale $s$ [Maraun, 2006], with the phase diagram describing the delay between two signals for all time/scale localizations given. The angular wavelet phase has different values (Figures 5-7): (i) for a phase shift close to $\pi$ or $-\pi$, the signals compared display phase opposition; (ii) for a phase shift close to 0 , the signals are in-phase, i.e., more rainfall when the Atlantic SSTs are warm; and (iii) a phase shift close to $\pi / 2$ or $-\pi / 2$ shows a phase quadrature; in this case, the signals present a substantial delay, which is physically nearly impossible or difficult to interpret.

[15] In section 6, we break down the North Atlantic SLP field (HadSPL2r: $25^{\circ} \mathrm{N}-88^{\circ} \mathrm{N}, 90^{\circ} \mathrm{W}-40^{\circ} \mathrm{E}$ ) into empirical 

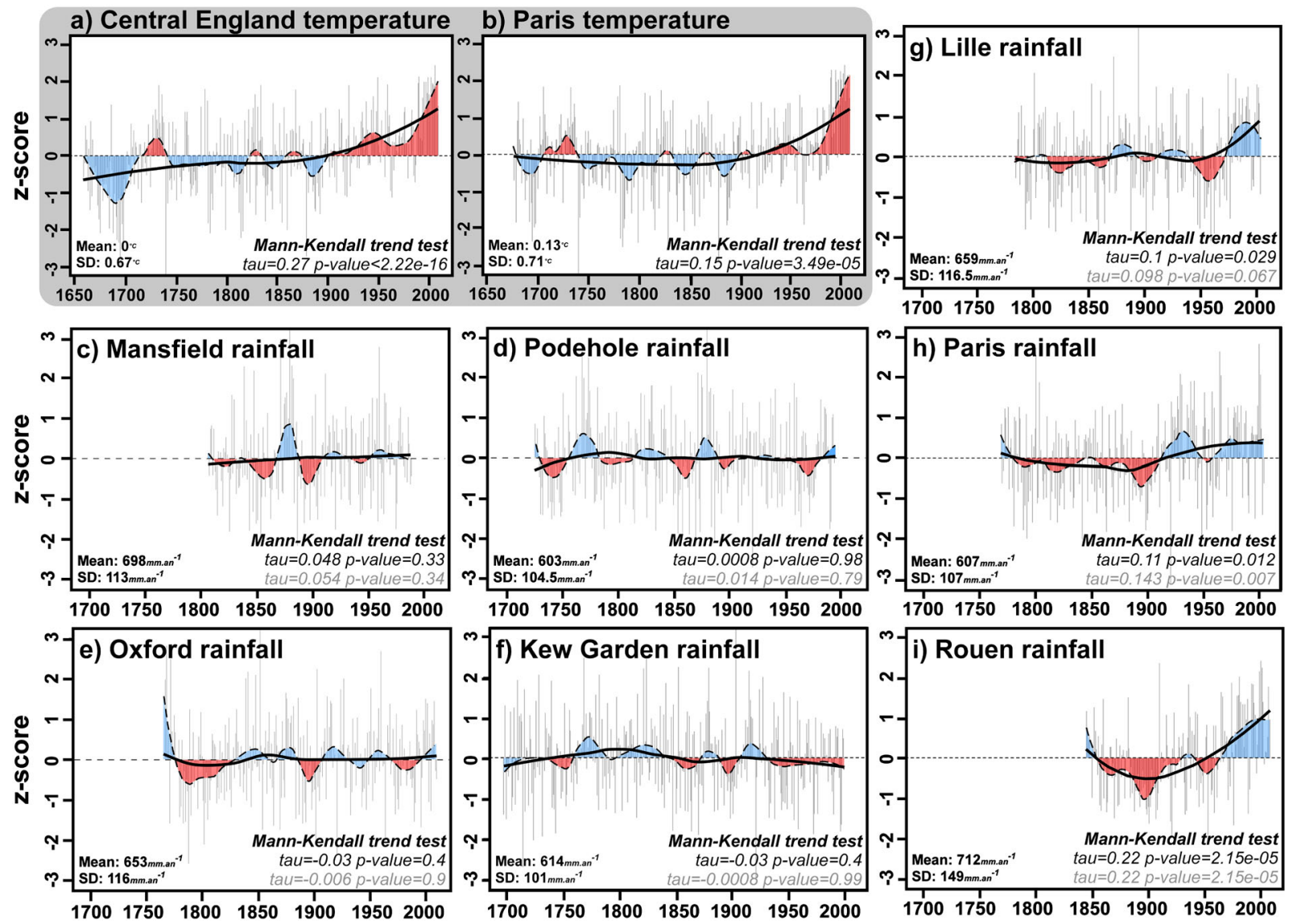

Figure 2. Time evolution of standardized annual temperature and rainfall amounts in England and northern France. (a, b) General trend (bold lines) and 50 year LOESS regression (dashed lines) of homogeneous temperature indices of the CET and Paris indices. (c-f) Same for the England rainfall amounts (Mansfield, Podehole, Oxford, and Kew Garden). (g-i) Same for the rainfall amounts in northern France (Lille, Paris, and Rouen). Blue (red) shaded displayed negative (positive) multidecadal trend for temperature and conversely for rainfall. The trend intensity (tau) and statistical significance (two-sided $p$ value) are evaluated using the Mann-Kendall trend test since the beginning of recorded data (black) and a common data period (since 1845; grey). The means and standard deviations of the original series before standardization are provided on the figure.

orthogonal functions (EOFs) [Preisendorfer, 1988] of previously filtered data. First, deseasonalized patterns of North Atlantic SLPs were computed by subtracting the monthly interannual mean from each corresponding month for all the time series from the grid. Second, each of the 486 SLP time series from the grid was detrended by removing a LOESS model and subsequently filtered out using Fourier transform according to the time scales identified as significant co-oscillations between NAOr and rainfall by wavelet coherence. Then, EOFs of filtered data can be used to identify North Atlantic SLP patterns associated with multidecadal and interdecadal time scales.

\section{Temperature and Rainfall Since the 17th Century}

\subsection{Long-Term Trend and Variability}

[16] The observations on temperatures are highly similar between the CET and Paris indices (Figures $2 \mathrm{a}$ and $2 \mathrm{~b}$ ). Both series have presented a positive trend (warmer) since the beginning of the 20th century (in England since 1904 and in Paris since 1918; solid line, Figures 2a and 2b). As expected, this positive trend appears significant in the Mann-Kendall trend test (tau: $0.15-0.27, p$ value: $2.22 \mathrm{E}-16$ to $3.49 \mathrm{E}-5$; Figures $2 \mathrm{a}$ and $2 \mathrm{~b}$ ) with autocorrelation coefficients of 0.4 and 0.12 for lag $k=1$ in the CET and Paris indices, respectively. Nonetheless, LOESS regressions using $\sim 50$ year smoothing windows show that the warm periods became more frequent from 1820 (period at the end of the Little Ice Age; dashed line, Figures $2 \mathrm{a}$ and $2 \mathrm{~b}$ ). Since the beginning of the 20th century, in addition to the intensity of this widely discussed warming, the persistence of warm anomalies has been observed (Figures $2 \mathrm{a}$ and $2 \mathrm{~b}$ ).

[17] For rainfall in England (solid line, Figures 2c-2f), the autocorrelation coefficients (lower than 0.007 for lag $k=1$ ) were never significant at the $95 \%$ confidence limit, and no trend could be detected according to the Mann-Kendall trend test since the beginning of recorded data (tau: -0.03 to $0.048, p$ value: $0.33-0.98$ ) and for the common period (tau: -0.006 to $0.054, p$ value: $0.34-0.99)$. Nonetheless, multidecadal rainfall variability $(\sim 50$ year smoothing 

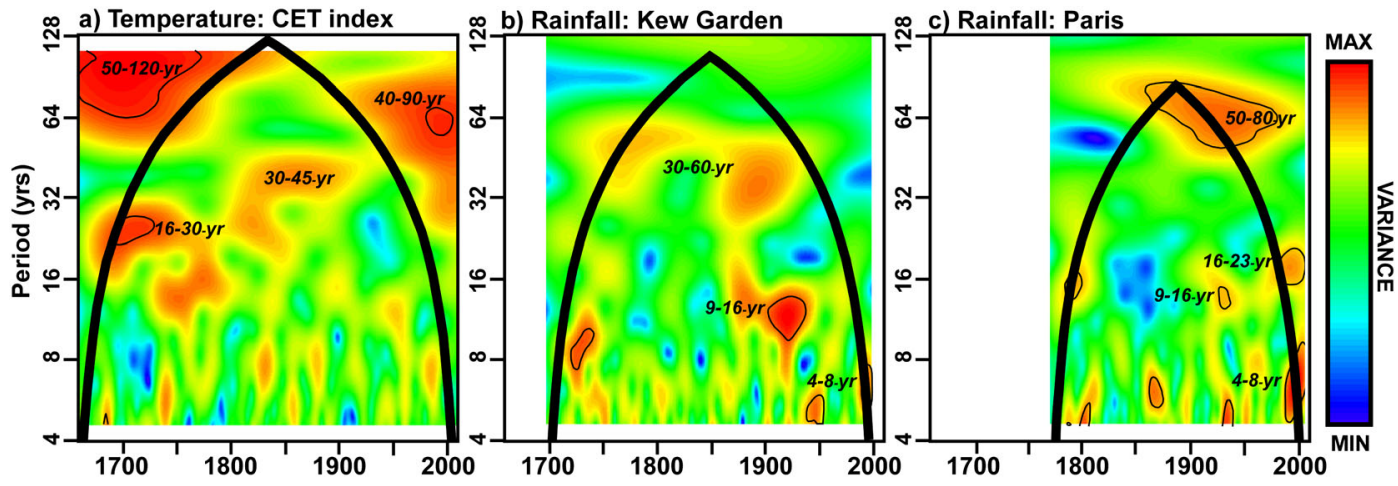

Figure 3. CWT applied to mean temperatures and to monthly rainfall amounts of the longest time series: (a) CET index, (b) rainfall at Kew Garden, and (c) rainfall in Paris. Bold line delineates the so-called cone of influence under which power is likely to be underestimated as a consequence of zero padding. Thin contour lines show the $90 \%$ confidence limits (Monte Carlo simulation).

windows) clearly demonstrates alternating periods of rainfall excesses and deficits before the 20th century (dashed line, Figures 2c-2f). The lag-1 autocorrelation coefficients are not statistically significant in France (except for Rouen, with a coefficient lower than 0.39 for lag $k=1$ ). Contrary to England, the results of the Mann-Kendall trend test on French time series in both time periods (all recorded periods: tau: $0.1-0.22$; $p$ value: $2.15 \mathrm{E}-5$ to 0.029 ; common period: tau: $0.098-0.22 ; p$ value $=2.15 \mathrm{E}-5$ to 0.067 ) show that the general rainfall trend is much more pronounced (Figures $2 g-2 \mathrm{i}$ ). It has been increasing since the end of the 19th century; the intensity of the increase is not discussed here since it depends on the length of the series (solid line, Figures $2 g-2 i$ ). Moreover, LOESS regressions using 50 year smoothing windows demonstrate strong variability in the rainfall marked by alternating periods of excess and shortage (dashed line, Figures $2 \mathrm{~g}-2 \mathrm{i}$ ). This variability seems more intense after 1850 in Paris and Rouen and since 1930 in Lille (dashed line, Figures 2g-2i).

[18] Although the temperature trends are similar in England and northern France, rainfall presents a strong regional contrast on either side of the English Channel. Furthermore, the changes observed in the temperature series could be in agreement with the changes observed in the rainfall in northern France, contrary to the rainfall in England. Moreover, with $\sim 50$ year smoothing windows, the results highlight the presence of well-structured low-frequency fluctuations that are very localized in time.
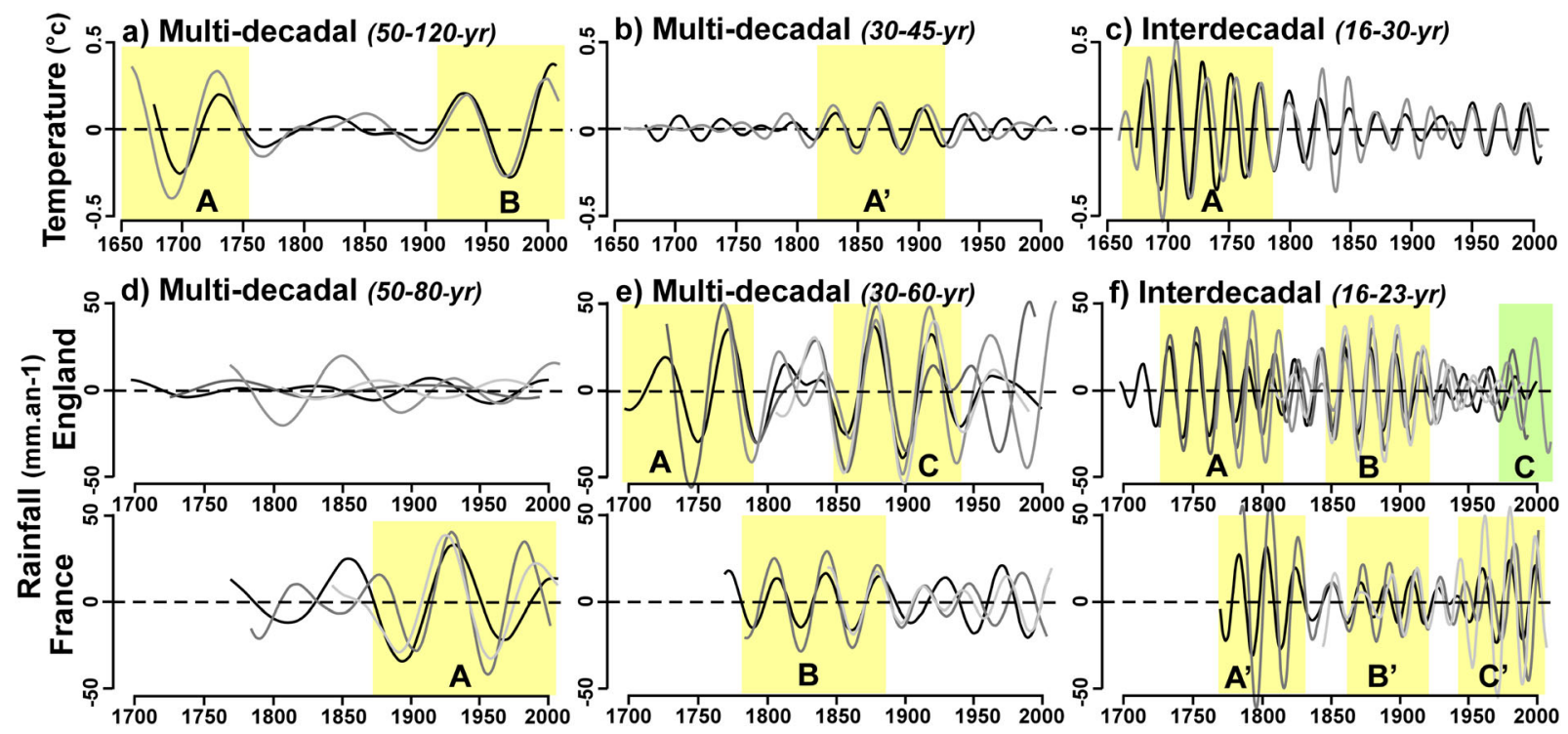

Figure 4. Reconstruction using inverse fast Fourier transform of the multidecadal and interdecadal time scales of temperature $\left({ }^{\circ} \mathrm{C}\right)$ and rainfall $\left(\mathrm{mm} \mathrm{yr}^{-1}\right)$ variability in England and northern France. (a-c) Reconstruction of multidecadal (50-120 and 30-45 years) and interdecadal (16-30 years) variability of the CET index (grey lines) and the Paris index (black lines). (d-f) Same for rainfall in England (black to light grey lines: Kew Garden, Podehole, Oxford, and Mansfield) and northern France (black to light grey lines: Paris, Lille, and Rouen). A, B, and C show the periods of high amplitude of a given variability time scale (yellow: common to all rain gauge stations; green: observed on a few rain gauge stations). 
a) Coherence and Phase: CET - AMOr

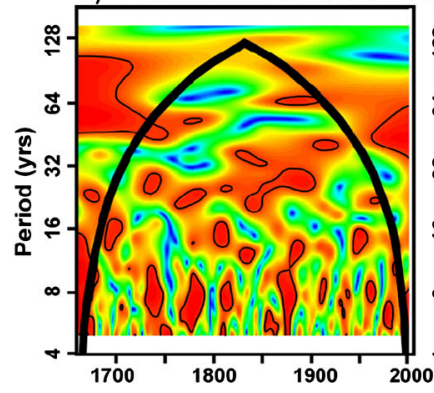

b) Coherence and Phase:

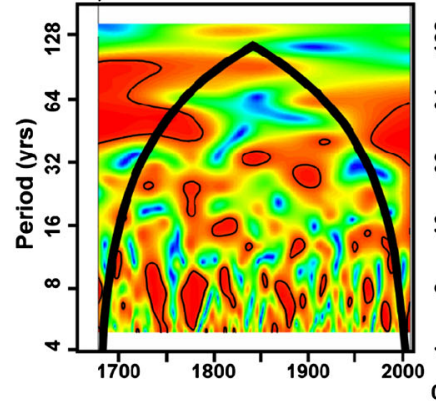

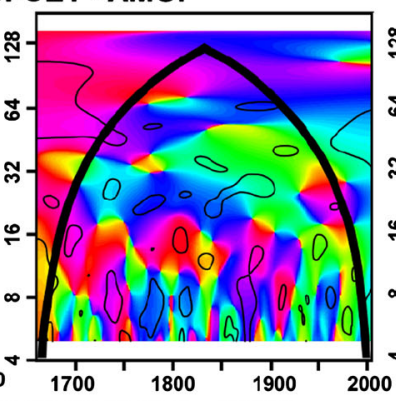

: Paris index - AMOr

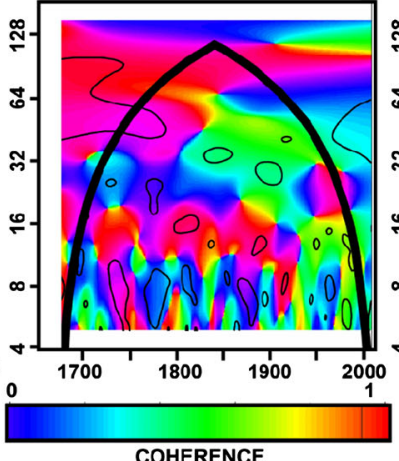

c) Coherence and Phase: CET - NAOr
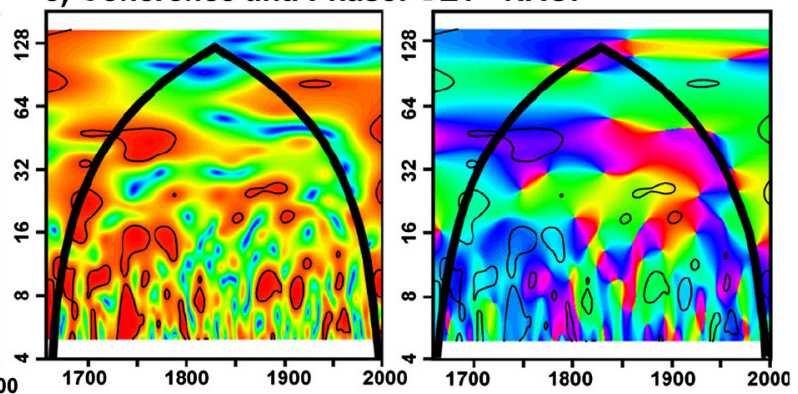

d) Coherence and Phase: Paris index - NAOr
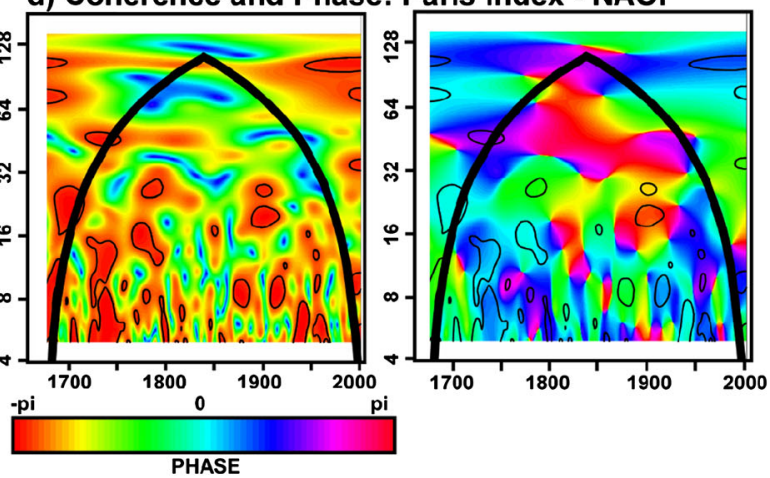

Figure 5. Wavelet coherence and phase between the temperature indices $\left({ }^{\circ} \mathrm{C}\right)$ of England and northern France and North Atlantic climatic oscillations (AMOr and NAOr indices). (a, b) Wavelet coherence and phase between the CET index and the Paris index with the AMOr index. (c, d) Same with the NAOr index. Bold lines delineate the so-called cone of influence under which power is likely to be underestimated as a consequence of zero padding. Thin contour lines show the pointwise significance test at the $90 \%$ level (critical value $=0.904$ ). On the phase diagrams: red indicates an angular phase $=\pi$ or $-\pi$, a phase opposition between the two signals; light blue indicates an angular phase $=0$, or a phase relation between the two signals; green indicates an angular phase $=\pi / 2$ or a slight negative delay between the two signals, which remains interpretable; all other colors indicate a phase quadrature presenting a noninterpretable delay.

\subsection{Time Scales of Temperature and Rainfall Variability}

[19] Temperatures in England (CET index) display several time scales of variability (Figure 3a): $50-120$ year multidecadal (or 40-90 year after 1900, only on the CET index) and 30-45 year multidecadal, one 16-30 year interdecadal, and also quasidecadal to interannual modes of lesser importance.

[20] The application of CWT to these two sectors reveals different time scales of rainfall variability (Figures $3 \mathrm{~b}$ and $3 c)$. In England (Kew Garden), the wavelet spectrum shows one 30-60 year multidecadal, one 9-16 year quasidecadal, and one 4-8 year interannual (Figure $3 b$ ) time scale. In France (Paris), the wavelet spectrum reveals one 50-80 year multidecadal scale, one 16-23 year interdecadal scale, one 9-16 year quasidecadal scale, and one 4-8 year interannual scale (Figure 3c).

[21] After reconstruction of the multidecadal and interdecadal time scales of temperature variability $(50-120$, 30-45, and 16-30 years), the temperature indices in both Paris and central England display similar time evolutions (Figures 4a-4c). Before 1800, both multidecadal (50-120 years) and interdecadal (16-30 years) scales show high amplitudes (phase A, Figures $4 \mathrm{a}$ and $4 \mathrm{c}$ ). In the 19th century (phase $\mathrm{A}^{\prime}$ ), a reinforcement of the 30-45 year multidecadal variability is detected (Figure 4b). Then, in the 20th century, the 50-120 year (or 40-90 year in the CET index) variability is reinforced as well (phase B, Figure 4a).

[22] For all rain gauge stations, the fluctuations in amplitude of multidecadal and interdecadal variability $(50-80$, 30-60, and 16-23 years) were compared (Figures $4 \mathrm{~d}-4 \mathrm{f}$ ). The 50-80 year variability is reinforced at the end of the 19th century in northern France (Figure 4d), while it is not significant in England (no peak detected on this scale; Figures $4 \mathrm{~b}$ and $4 \mathrm{~d}$ ). The 30-60 year multidecadal variability, expressed in England on the CWT (Figure 3b), also occurs in northern France (Figure 4e). However, its amplitude fluctuates over time in different manners in the two regions (Figure 4e): in England, the 30-60 year variability is stronger during the 1740-1800 and 1850-1950 periods (phases A and $\mathrm{C}$ ); in France, this variability is more powerful between 1780 and 1870 (phase B). The 16-23 year interdecadal rainfall variability, which only appears in northern France on the CWT (Figure 3c), is also observed in England with the same time evolution (Figure 4f). Three phases of interdecadal variability reinforcement are detected (Figure 4f): between 1730 and 1820 (phase A-A'), between 1850 and 1920 (phase B$\mathrm{B}^{\prime}$ ), and after 1940-1950 (phase $\mathrm{C}^{\prime}$ ), only observed at Podehole and Oxford in England (phase C).

[23] Thus, three multidecadal and interdecadal modes of variability are identified in England and northern France for temperature (50-120, 30-45, and 16-30 years) and rainfall $(50-80,30-60$, and 16-23 years). As presented in 

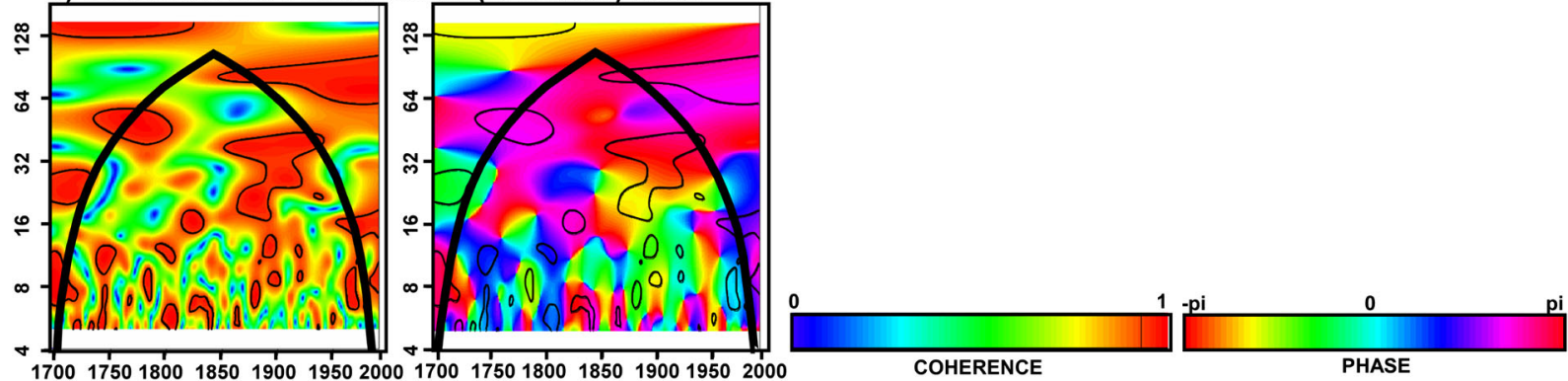

b) Coherence and Phase: rainfall (Podehole) - AMOr
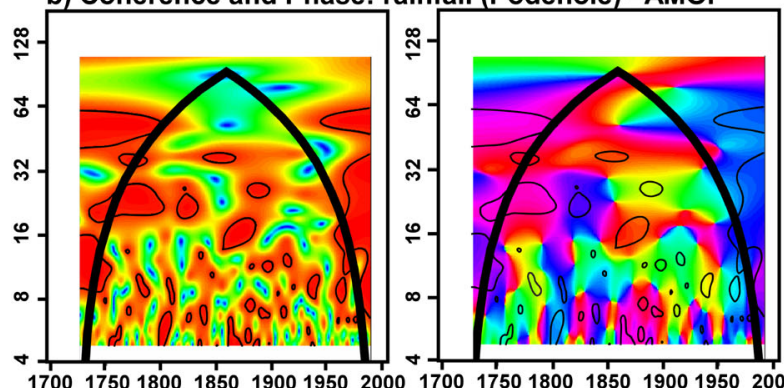

e) Coherence and Phase: rainfall (Paris) - AMOr

c) Coherence and Phase: rainfall (Oxford) - AMOr
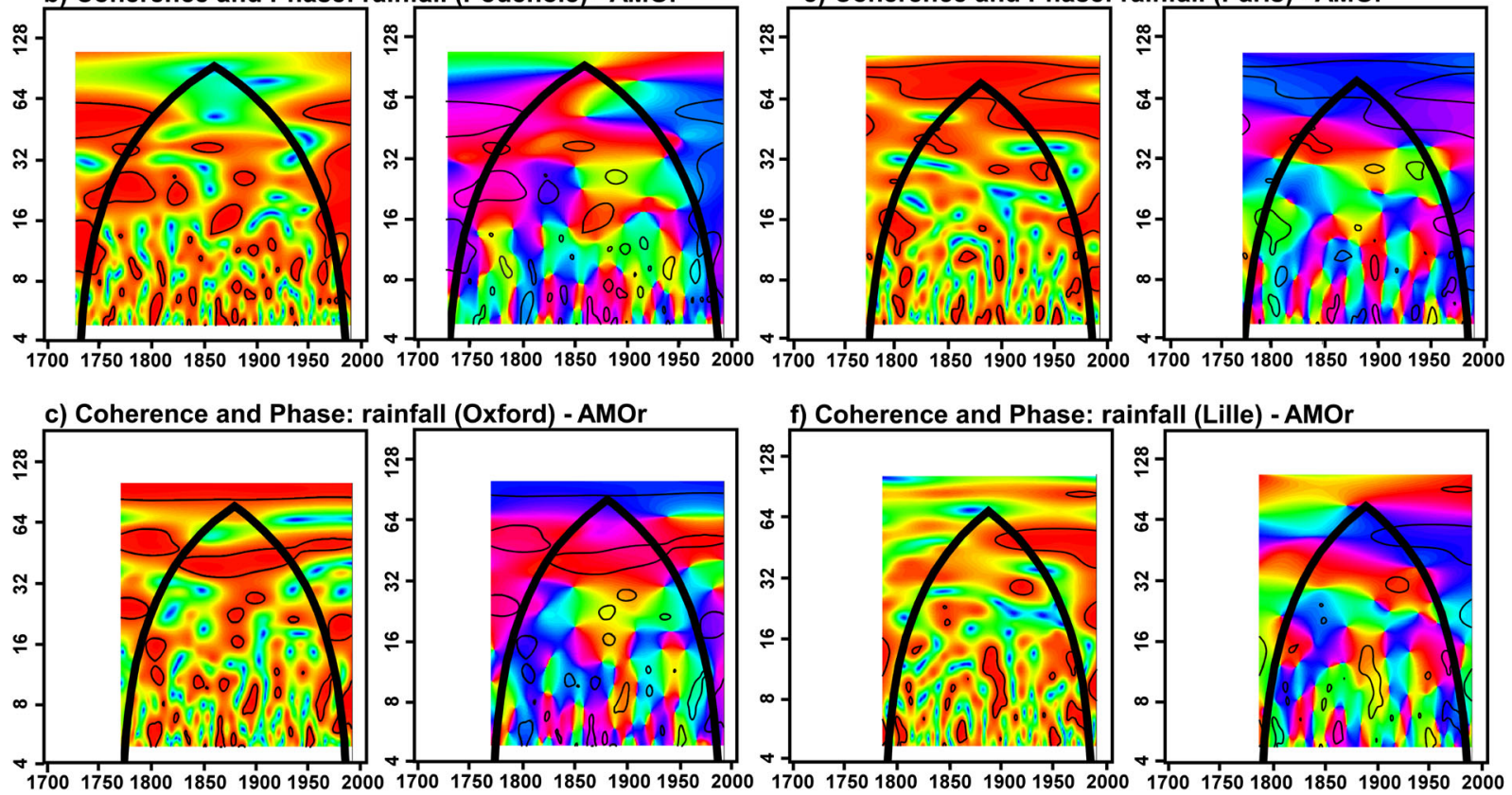

d) Coherence and Phase: rainfall (Mansfield) - AMOr
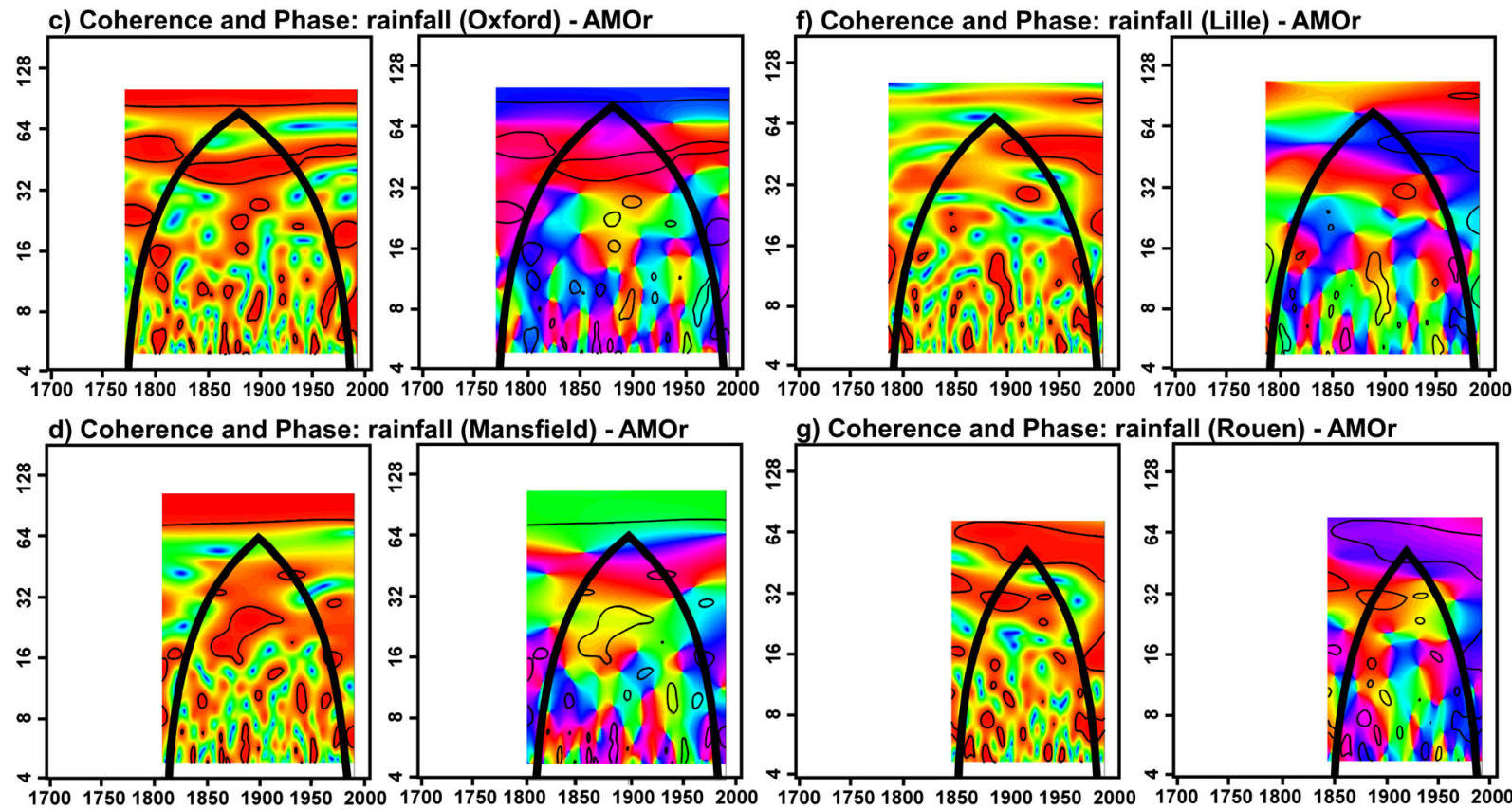

Figure 6. Wavelet coherence and phase between the monthly rainfall amounts of England and northern France with the AMOr index. $(\mathrm{a}-\mathrm{d})$ Wavelet coherence and phase between the England rainfall amounts (Kew Garden, Podehole, Oxford, and Mansfield) and the AMOr index. (e-g) Same in northern France (Paris, Lille, and Rouen). Same legends as Figure 5 (critical value $=0.921$ ).

section 3.1, these fluctuations in temperature are very similar on both sides of the English Channel. On the other hand, concerning rainfall, a strong regional contrast exists between England and northern France, which is observed most particularly on multidecadal scales (50-80 and 30-60 years). Moreover, the analysis of multidecadal and interdecadal time scales of variability has demonstrated a number of periods of high amplitude (whether or not they are shared by all the time series studied). Furthermore, these periods of increasing regional variability in temperature and rainfall could be related to North Atlantic climate variability.

\section{Co-Oscillations Between Regional Climate} Variables and North Atlantic Climate Indices

\subsection{Temperature Versus AMOr/NAOr}

[24] The temperature in central England and Paris exhibited two periods of high amplitude on the 50-120 year multidecadal scale (A: before 1800; B: 20th century; Figure $4 a)$. Such increases seem to be linked with the AMOr index as emphasized by the wavelet coherence diagram (Figures 5a and 5b). During period A, the 50-120 year variability of the wavelet phase spectrum displays a phase 
a) Coherence and Phase: rainfall (K. Garden)-NAOr
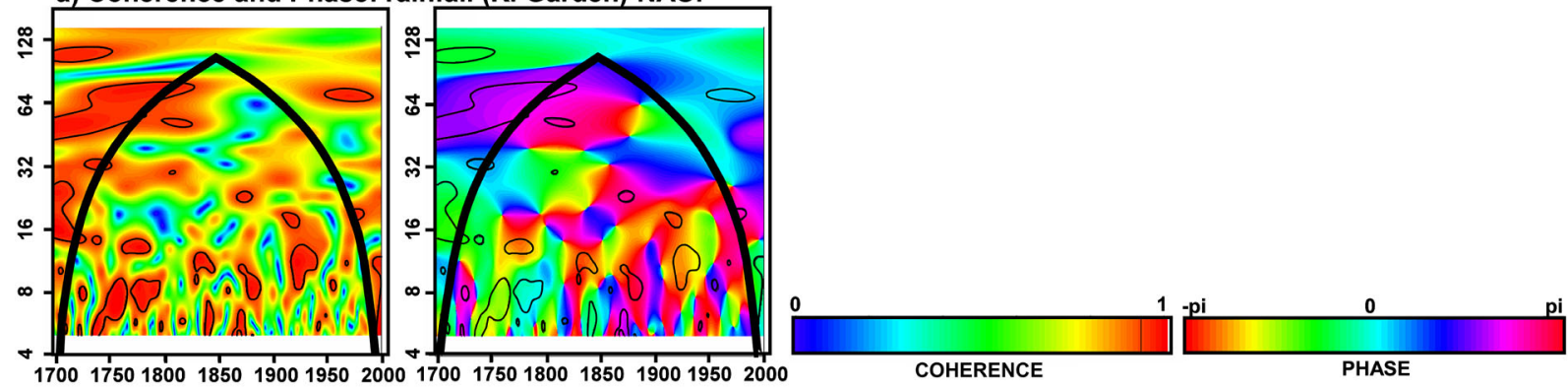

b) Coherence and Phase: rainfall (Podehole) - NAOr
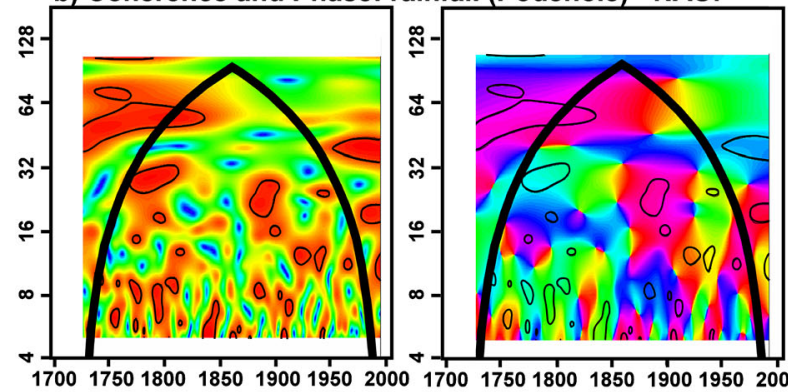

e) Coherence and Phase: rainfall (Paris) - NAOr

c) Coherence and Phase: rainfall (Oxford) - NAOr
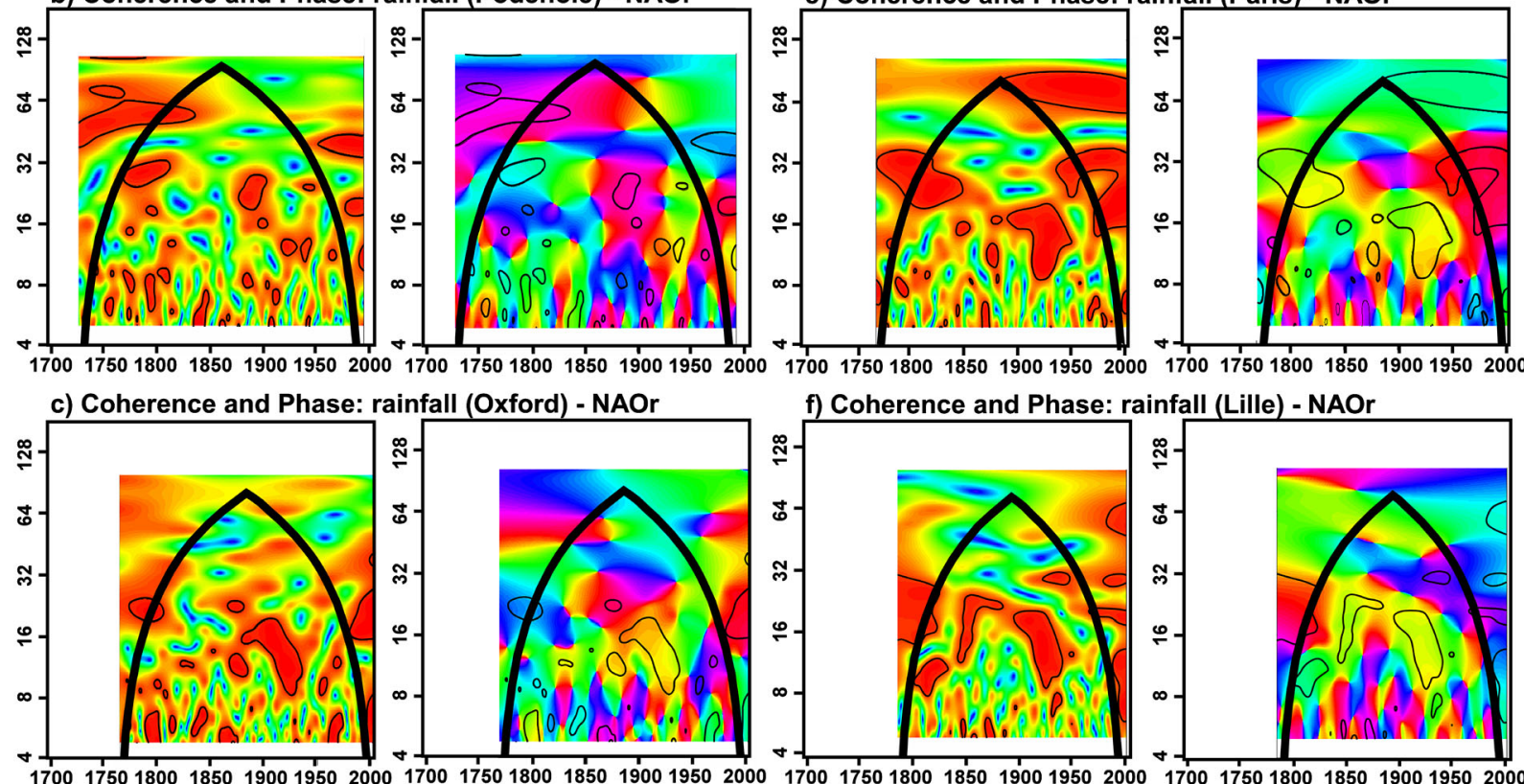

d) Coherence and Phase: rainfall (Mansfield) - NAOr
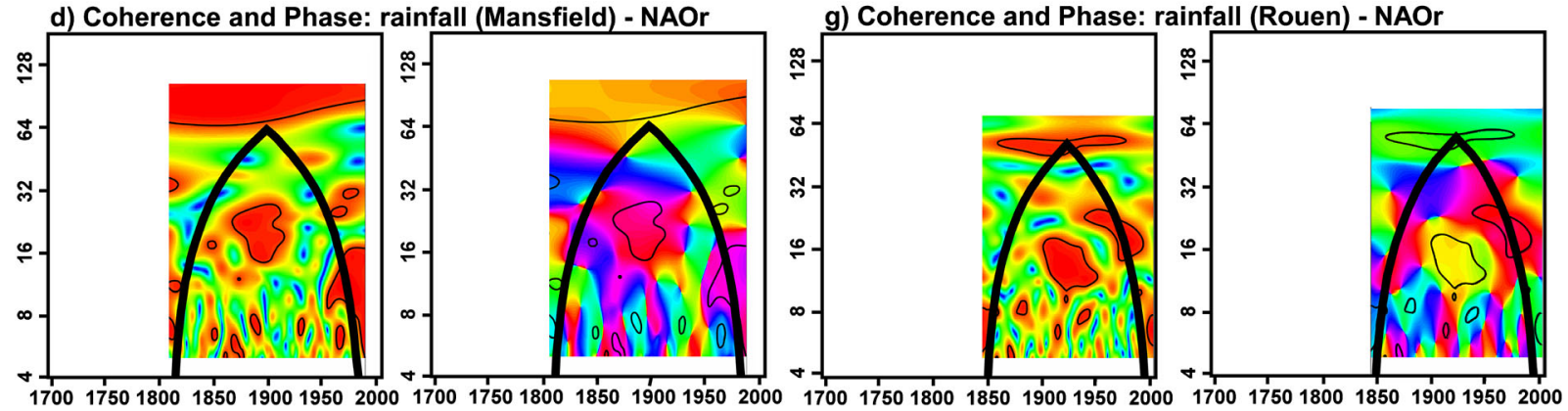

Figure 7. Same as Figure 6 but with the NAOr index (critical value $=0.921$ ).

opposition (i.e., warmer North Atlantic SSTs associated with cooler temperature in England and northern France; Figures $5 \mathrm{a}$ and 5b). Conversely, during period B, since 1900, the 50-120 year variability is in-phase with AMOr (i.e., warmer North Atlantic SSTs associated with warmer temperature in England and northern France; Figures 5a and 5b). The $\mathrm{A}^{\prime}$ period (19th century), referring to the transition period, is marked by high amplitude of 30-45 year multidecadal variability, coherent and in-phase with the AMOr index (Figures 5a and 5b). The interdecadal variability of temperature and the AMOr index is occasionally coherent and presents a phase change (the signals first display phase opposition and then are in-phase) at the beginning of the 20th century (Figures $5 \mathrm{a}$ and $5 \mathrm{~b}$ ).
[25] Coherence between temperature and the NAOr index is observed mainly from interdecadal (16-36 years) to interannual scales, and the two signals are in-phase most of the time (Figures $5 \mathrm{c}$ and $5 \mathrm{~d}$ ).

[26] The periods of increasing multidecadal (50-120 and 30-45 years) and interdecadal (16-30 years) temperature variability in England and France seem to be related to the AMOr index. These co-oscillations display phase changes between the 18th and 20th centuries, suggesting changes in the oceanic circulation and/or in the seasonal characteristics of associated large-scale teleconnections. According to van der Schrier and Weber [2009], a northward displacement of the Gulf Stream system and a greater heat flux are observed during the 1790-1825 A.D. period. Moreover, 
Knight et al. [2006] showed that the correlations between the CET index and the AMO are only significant and positive in JJA and SON but can be reversed in DJF. Thus, as has been observed since 1990 [Sutton and Dong, 2012], it would be possible that the DJF correlation is stronger on multidecadal and interdecadal scales before 1800 .

[27] In contrast, the relationship between temperature and the NAOr index seems weaker and tends to be detected across the highest-frequency time scales.

\subsection{Rainfall Versus AMOr}

[28] The 50-80 year multidecadal rainfall variability in northern France has exhibited high amplitudes since the end of the 19th century (phase A, Figure 4d). The latter period appears coherent with the AMOr index but in the quadrature phase (i.e., rainfall changes before the AMOr index; Figures $6 \mathrm{e}-6 \mathrm{~g})$. The $30-60$ year multidecadal variability, presenting three periods of high amplitude (A: 1740-1800 in England, B: 1780-1870 in France, C: 1850-1950 in England; Figure 4e), is coherent and displays a phase opposition with the AMOr index (i.e., more rainfall when the North Atlantic SSTs are cooler; Figure 4). However, coherence levels are not equivalent from one gauge station to another and can be nonsignificant, as in Lille during phase B (Figure 6).

[29] The 16-23 year interdecadal scale is characterized by a low coherence level between the AMOr index and rainfall at Kew Garden, Podehole, Oxford, Mansfield, and Paris during the period B-B' (i.e., 1850-1920) (Figures 6a-6e).

\subsection{Rainfall Versus NAOr}

[30] On the multidecadal scale (50-80 years), rainfall variability at Kew Garden and Podehole is coherent with the NAOr index (Figures $7 \mathrm{a}$ and $7 \mathrm{~b}$ ). This coherent time scale of variability displays a phase opposition before 1850 , whereas the signals are in-phase after 1950 (i.e., negative NAO was associated with greater rainfall before 1850 , and after 1950, positive NAO is related to greater rainfall) despite a decrease in coherence (Figures 7a and 7b). In northern France, the multidecadal rainfall variability and the NAOr index are also coherent and in-phase at the end of the 19th century for Paris and Rouen (Figures 7e and 7g), and after 1950 for Lille (Figure $7 \mathrm{f}$ ). The increase of the 50-80 year multidecadal rainfall variability at the end of the 19th century (period A, Figure 4d) could therefore be related to the NAOr index. Even though this relationship seems to hold in Podehole and Kew Garden, it would not have a significant impact on these rainfall series (Figures $3 \mathrm{~b}$ and $4 \mathrm{~d}$ ). However, this 50-80 year multidecadal time scale may be more clearly expressed at the seasonal scale and for particular seasons.

[31] In the interdecadal rainfall variability scale (16-23 years), three periods of high amplitude were observed (Figure 4f): the 1730-1820 period (period $\mathrm{A}-\mathrm{A}^{\prime}$ ); the 1850

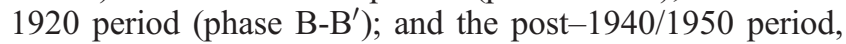
(period $\mathrm{C}^{\prime}$ ), only observed at Podehole and Oxford in England (period $\mathrm{C}$ ). Although during period $\mathrm{A}-\mathrm{A}^{\prime}$ the relationship between rainfall and the NAOr index is not perfectly clear, the same does not hold true for periods B and C-C (Figure 7). The NAOr index is coherent and is in phase opposition with rainfall variability in England in phase B
(Figures $7 \mathrm{a}-7 \mathrm{~d}$ ), and during the period $\mathrm{C}-\mathrm{C}^{\prime}$ in northern France (with a greater delay at Lille), at Podehole and Oxford (Figures 7b, 7c, 7e, and 7g).

[32] Three interpretations can be made to explain the phase changes observed in the rainfall/NAOr. First, positive summer NAO, which is displaced significantly northeastward compared to winter [Hurrell and Deser, 2009], implies dry conditions over NW Europe [Folland et al., 2009]. Thus, changes in the seasonal aspect of these multidecadal and interdecadal teleconnections should be pursued. Second, a multidecadal and interdecadal northeastward/southwestward shift of the NAO pattern could occur independently of the annual cycle over centuries. Third, multidecadal and interdecadal covariability scales are significantly affected by small-scale and transient meteorological phenomena such as other SLP patterns not related to the NAO and, therefore, may contain noise.

\section{Multidecadal and Interdecadal Anomalies of North Atlantic SLP Patterns Since 1850}

[33] The AMOr index seems representative of the North Atlantic SST variability observed, with strong correlation values $(r=0.64$ with the SSTs; $r=0.81$ with the AMO index according to Gray et al. [2004]). The contrary is true for the NAO index, which cannot optimally represent the spatial structure of the NAO pattern. A disadvantage of stationbased indices is that they are fixed in space and thus do not account for the displacement of the action centers on the seasonal scale and the existence of other SLP patterns [Barnston and Livezey, 1987; Cassou et al., 2004; Hurrell and Deser, 2009]. This actually constitutes one nonnegligible issue since the NAO pattern only accounts for approximately half of the total interannual variance in winter [Cassou et al., 2004].

[34] Over the 1850-2010 period, two series of filtered EOFs were constructed according to 50-80 year multidecadal and 16-23 year interdecadal variability scales to observe the multidecadal and interdecadal anomalies of the SLP fields and were compared with normal conditions (deseasonalized) (Figure 8). The 30-60 year multidecadal EOFs are not shown here since the NW European climate and the NAOr index were not coherent on this scale.

[35] First (Figure 8a), we compared the fractions of variance accounted for by the first 20 EOFs for the multidecadal (blue: 50-80 years) and interdecadal (green: 16-23 years) variations with the normal conditions (black lines). The multidecadal anomalies of the SLP field seem to be observed on the first two EOFs (Figure 8a). On the interdecadal scale, the variance fraction distribution of the SLP anomalies is closer to the normal conditions (Figure 8a). Therefore, the third EOF always presenting more than $10 \%$ of the total variance is also retained (Figure 8a).

[36] Second, we studied the SLP patterns of multidecadal and interdecadal anomalies compared to normal conditions (Figures 8b-8i). In normal conditions, according to our EOF calculation method, the first three EOFs identified were identical to those reported by Pauling et al. [2006] for the 1500-2002 period. EOF-1 (35\% of the total EOF variance) shows NAO patterns, consisting of a north-south dipole of anomalies with one center located over Greenland and the other center of the opposite sign spanning the central 


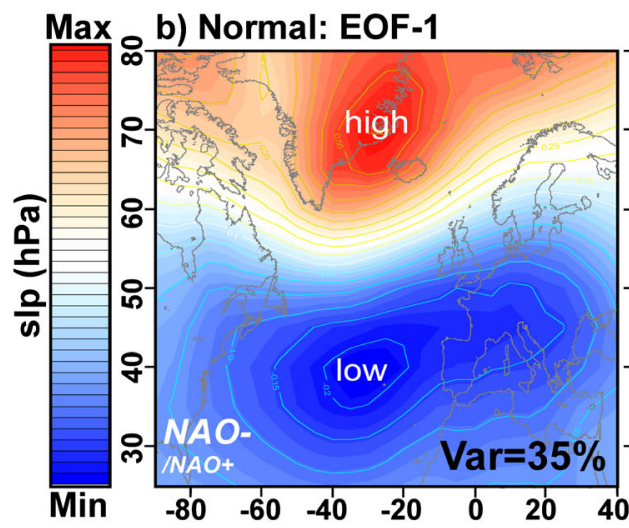

c) Normal: EOF-2
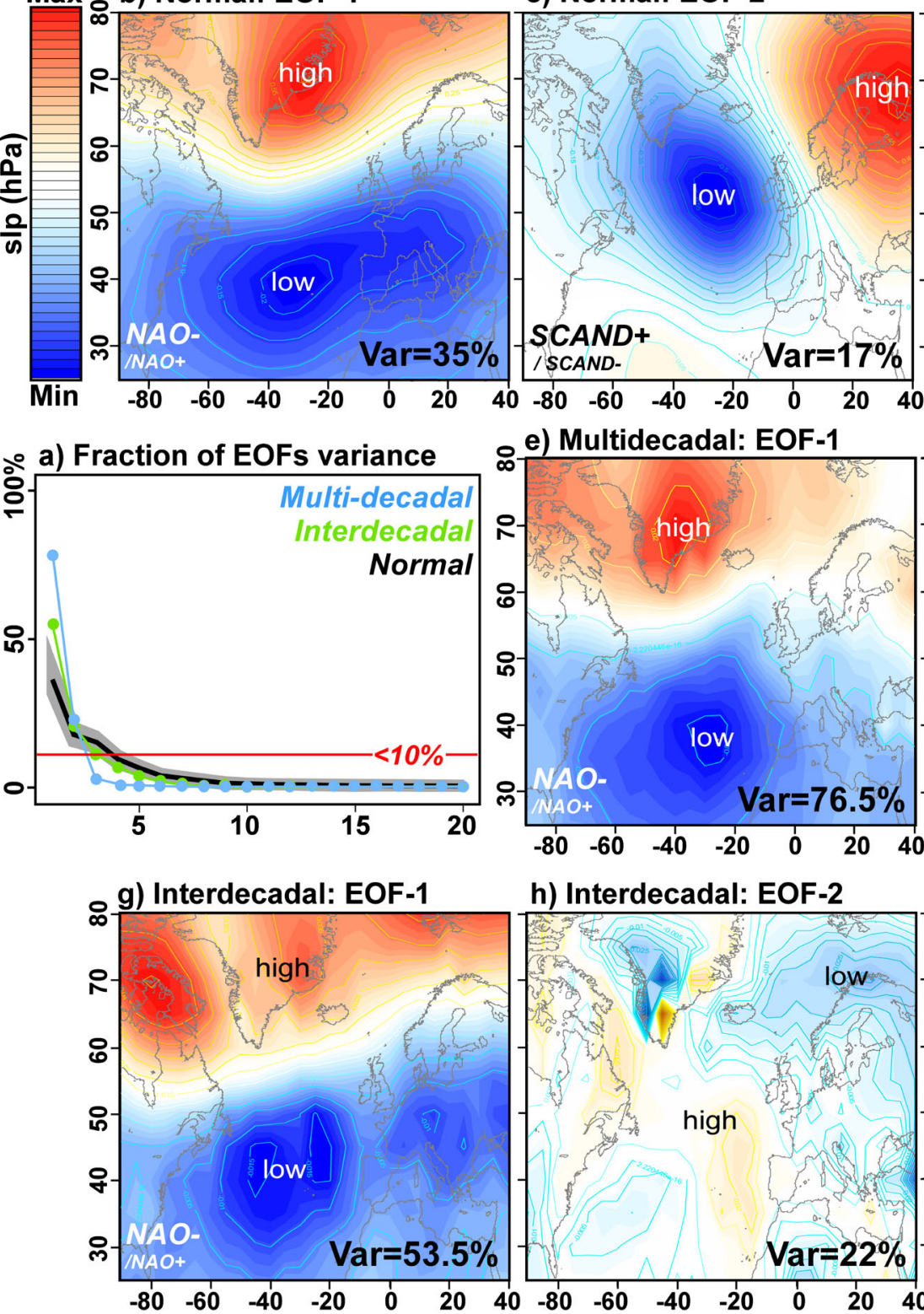

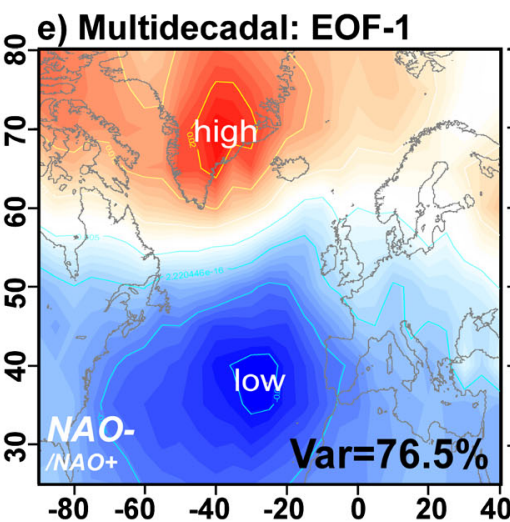

h) Interdecadal: EOF-2

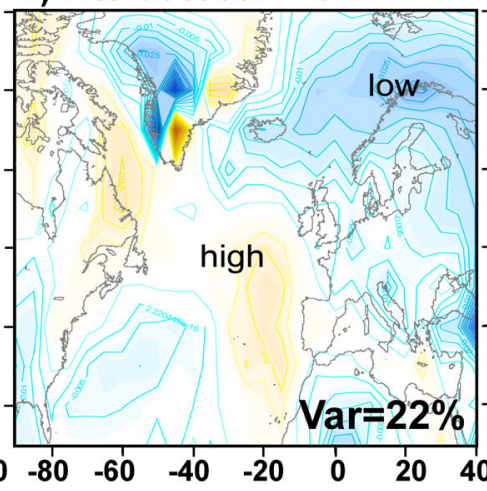

d) Normal: EOF-3

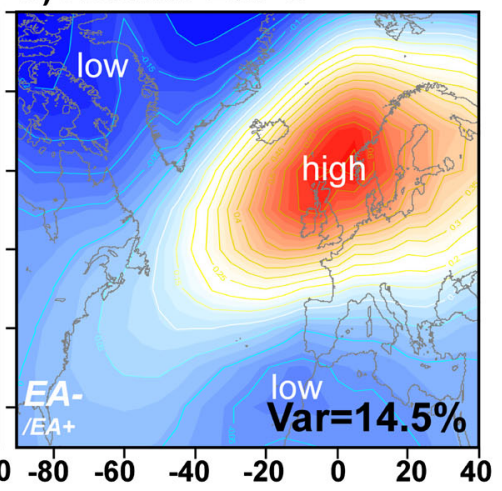

f) Multidecadal: EOF-2

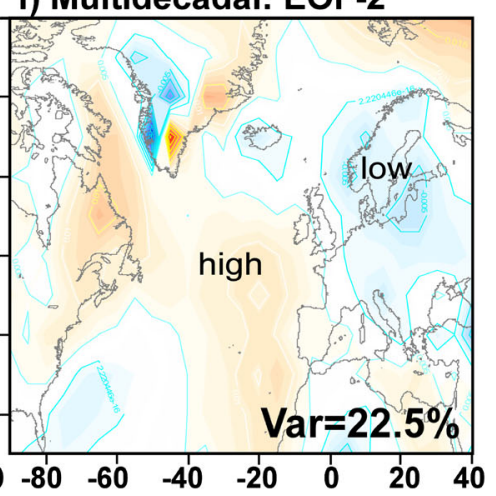

Figure 8. Reconstruction using the EOF of multidecadal (50-80 years) and interdecadal (16-23 years) anomalies of the North Atlantic SLP (hPa, HadSLP2r data set: $25^{\circ} \mathrm{N}-88^{\circ} \mathrm{N}, 90^{\circ} \mathrm{W}-40^{\circ} \mathrm{E}$ ) since 1850 and the percentage expressed of the total EOF variance. (a) Fraction of the variance expressed by the 20th EOFs at the multidecadal scale (blue), the interdecadal scale (green), and according to the normal deseasonalized conditions (black, standard deviation in grey). (b-d) EOF-1, EOF-2, and EOF-3 of the deseasonalized North Atlantic mean SLP. (e, f) EOF-1 and EOF-2 of the multidecadal North Atlantic mean SLP anomalies (50-80 years). (g, i) EOF-1, EOF-2, and EOF-3 of the interdecadal North Atlantic mean SLP anomalies (16-23 years). The EOFs presenting less than 10\% of the total variance are not represented.

latitudes of the North Atlantic between $35^{\circ} \mathrm{N}$ and $40^{\circ} \mathrm{N}$ (Figure $8 \mathrm{~b}$ ). EOF-2 (17\%; Figure 8c), similar to the structure of EOF-3 studied by Slonosky et al. [2000] and Luterbacher et al. [2002], shows a contrast between western and eastern Europe. Moreover, EOF-2 may be similar to the Scandinavia (SCAND) pattern and, therefore, to a component of meridional flow over Europe [Barnston and Livezey, 1987]. Moreover, the positive and negative phases of this pattern are associated with positive SLP anomalies, sometimes reflecting a blocking pattern over the Scandinavia and Atlantic ridge patterns, respectively [Cassou et al., 2004; Hurrell and Deser, 2009]. EOF-3 (14.5\%) is characterized by an SLP structure centered on the North Sea and simultaneously SLP with opposite signs over the NW Atlantic and North Africa (Figure 8d). This pattern shows a strong resemblance to the East Atlantic (EA) pattern [Barnston and Livezey, 1987], which is often interpreted as a southeastward shifted NAO pattern. 
[37] On multidecadal and interdecadal scales, the dominant SLP patterns (EOF-1) display NAO patterns (multidecadal and interdecadal: $76.5 \%$ and $53.5 \%$ of the total EOF variance; Figures $8 \mathrm{e}$ and $8 \mathrm{~g}$ ). At first glance, the 50 80 and 16-23 year covariability scales appear to be related to NAO patterns, particularly on the multidecadal scale $(76.5 \%$ of the total EOF variance), which reduces uncertainty. As for EOF-2, the SLP patterns associated with the multidecadal and interdecadal anomalies present a NE-SW dipole of anomaly centers spanning the whole region studied (Figures $8 \mathrm{f}$ and $8 \mathrm{~h}$ ). Moreover, an eastward shift of the Icelandic low is clearly detected. This spatial structure of the SLP anomaly could therefore modify zonal and meridional atmospheric circulations associated with the NAO and Scandinavia patterns. On the interdecadal scale, EOF-3 is characterized by a low-pressure zone extending from Greenland to North Africa and a high-pressure zone over NE America and Russia (Figure 8i). As a result, on the multidecadal and interdecadal scales, respectively, 22.5\% and $22+11 \%$ of the variance accounted for by EOFs could disturb the study of the relationship between rainfall and the NAO Index.

[38] We compared the time evolution of the multidecadal and interdecadal anomalies of the North Atlantic SLP (PC1 to PC-3) with (Figure 9): (i) 50-80 and 16-23 year scales of deseasonalized SLP patterns (NAO, SCAND, and EA) and (ii) the periods of increasing multidecadal and interdecadal rainfall variability linked to the NAOr index. On the multidecadal scale, the time evolution of PC-1 of the North Atlantic SLP anomalies is perfectly consistent with the multidecadal variability of the NAO pattern (Figure 9a). Thus, the in-phase relationship between the increase of 50-80 year rainfall variability could operate the NAO pattern (EOF-1; Figures 8a and 8e), whose variance is high during this period (in yellow on PC-1, Figure 9a). Nonetheless, at the end of the last century, this relationship may have been disturbed by the NE-SW anomaly pattern of the North Atlantic SLP (EOF-2, Figure 8f), whose variance is greater during this period (PC-2, Figure 9a). Moreover, this may be detected at Kew Garden, Podehole, and Lille, whose relationship with the NAOr index appears later (end of the 20th century; Figures 7a, 7b, and 7f) than at Paris and Rouen (Figures 7e and 7g). However, the time evolution of this anomaly is not consistent with the SCAND and EA patterns on the multidecadal scale (Figure 9a).

[39] On the interdecadal scale, although the time evolution of PC-1 of the North Atlantic SLP anomaly is perfectly consistent with the variability of the NAO pattern, this is not the case for the two periods of increasing rainfall variability (Figure 9b): period B (1850-1920) and period C-C' (after 1940-1950). During these periods, an increase of rainfall variability seems to be associated with variations in PC-2 (Figure 9b), i.e., the NE-SW dipole anomaly of the North Atlantic SLP (EOF-2, Figure 8h). This could explain the phase opposition between NAOr and the rainfall time series. Moreover, this anomaly of the North Atlantic SST could be linked to the excitation of the SCAND pattern and, after the longest time lag, the EA pattern on the interdecadal scale (Figure 9b). In other words, it may correspond to an excitation of the blocking pattern over Scandinavia and the Atlantic ridge pattern (SCAND, Figure 8c) and/or a southeastward shifted NAO pattern (EA, Figure 8d).

\section{Discussion and Conclusions}

[40] Since the Little Ice Age, the general trends and the multidecadal variability in temperature seem to be similar in England and northern France, contrary to the general trends for rainfall. The three time scales of variability dominating temperature (multidecadal: 50-120 and 30-45 years;
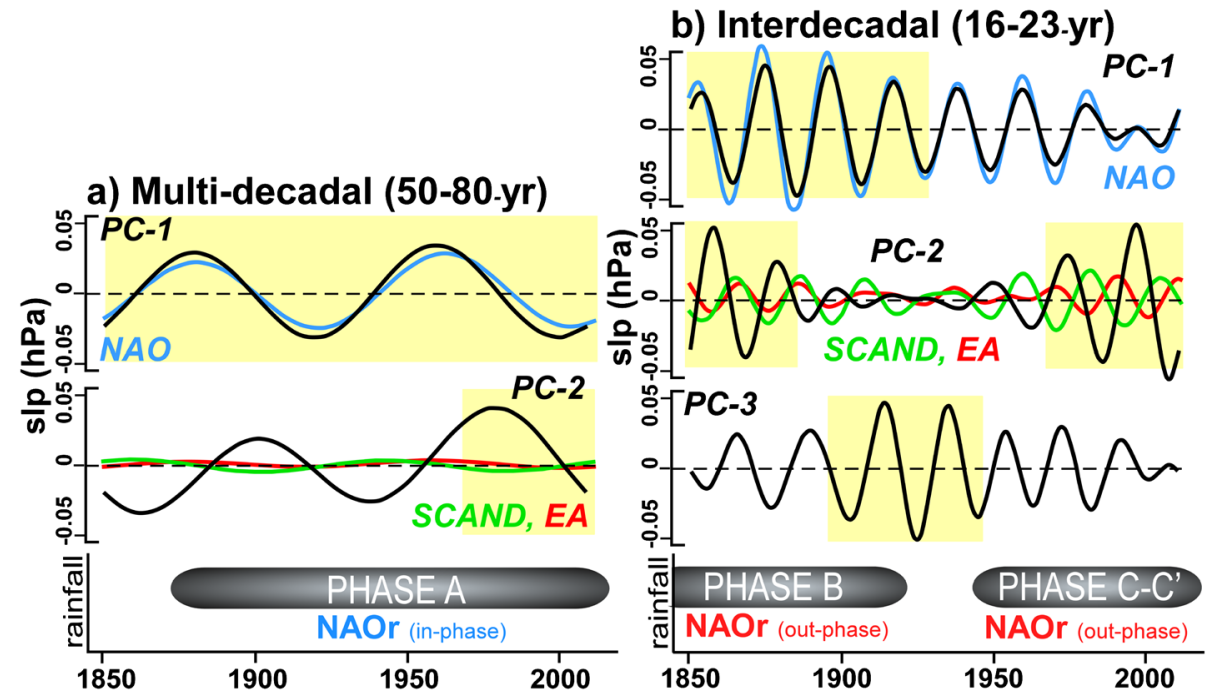

Figure 9. Time evolution of multidecadal and interdecadal climatic oscillations detected in North Atlantic SLP ( $\mathrm{hPa}, \mathrm{HadSLP} 2 \mathrm{r}$ data set: $\left.25^{\circ} \mathrm{N}-88^{\circ} \mathrm{N}, 90^{\circ} \mathrm{W}-40^{\circ} \mathrm{E}\right)$ and England and northern France rainfall variability. (a) Time evolution of multidecadal anomalies (PC-1 and PC-2) compared to the multidecadal scales of deseasonalized SLP patterns (NAO: blue; SCAND: green; EA: red) and to the periods of high amplitude in multidecadal rainfall variability (grey bars) coherent (in-phase: blue; phase opposition: red) with the NAOr indices. (b) Same for the interdecadal variations. The periods of high amplitude $(<25$ th and $>75$ th percentiles $)$ of the PCs are illustrated in yellow. 
interdecadal: 16-30 years) display obvious co-oscillations in England and northern France, which is not the case for that characterizing rainfall variability (multidecadal: $50-80$ and 30-60 years; interdecadal: 16-23 years). This suggests that the large-scale climate oscillations control temperature and rainfall differently.

[41] The statistical relationships between temperature and the North Atlantic SSTs (AMOr index) across the multidecadal and interdecadal time scales reveal changes between the Little Ice Age and the present time. Increasing multidecadal and interdecadal temperature variability in England and northern France corresponds to phase opposition with the AMOr index (i.e., cooler SSTs were associated with warmer temperatures) before 1800; afterward, the North Atlantic SSTs and temperature variability are in-phase (i.e., warmer SSTs were associated with warmer temperatures). Such multidecadal co-oscillations in North Atlantic SSTs match those of the Atlantic thermohaline circulation [Delworth et al., 1997; Enfield et al., 2001]. Thus, the phase changes in the observed temperature/AMOr relationships could be linked to a northward displacement of the Gulf Stream system and a greater heat flux during the 1790 1825 A.D. period [van der Schrier and Weber, 2009]. Moreover, changes in the seasonal characteristics of multidecadal and interdecadal teleconnections cannot be excluded. Furthermore, the in-phase relationship between temperature and the NAOr index remains weak because it is restricted to the interdecadal and interannual scales (not highly expressed on the CWT of the CET index).

[42] Nonstationary behaviors of relationships between rainfall and $\mathrm{AMO} / \mathrm{NAO}$ indices are also detected since the end of 17th century. Multidecadal and interdecadal rainfall variability shows wavelet coherence over 30-60 years with AMOr and 50-80 and 16-23 years with NAOr. However, during the periods of high amplitude of the 30-60 year variability (A: 1740-1800 in England; B: 1780-1870 in France; C: 1850-1950 in England), the rainfall and AMOr index are in phase opposition (i.e., colder North SSTs associated with greater rainfall). On the other hand, the 50-80 year variability shows the following: (i) in England, a phase opposition with the NAOr index before 1850, whereas the signals are in-phase after 1950 (i.e., negative NAO was associated with greater rainfall before 1850 , and after 1950 , positive NAO is related to greater rainfall); (ii) in northern France, rainfall and NAO are in-phase at the end of the 19th century for Paris and Rouen and, after 1950, for Lille. Moreover, the interdecadal variability presents a phase opposition with the NAOr index in England during phase B (1850-1920) and during C-C' (after 1940-1950) in northern France, Podehole, and Oxford. The latter result is consistent with previous hydrological studies conducted on hydrosystems over shorter time periods in northern France and England [Slimani et al., 2009; Massei et al., 2010; Holman et al., $2011]$.

[43] The phase changes in the NAO/rainfall relationships are in agreement with those reported by Mokhov et al. [2000], who found that, using interpretations of two 1000 year numerical simulations, decadal variability of NAO regimes clearly varied over centuries: recent studies have documented the impacts of minimum and maximum solar activities [Kodera and Kuroda, 2005; Van Loon et al., 2012] and increasing greenhouse gases emissions
[Osborn, 2004] on long-term NAO variability that might well be involved here. Moreover, these multidecadal and interdecadal teleconnections with NAO may involve long-term changes of the annual cycle [Folland et al., 2009; Hurrell and Deser, 2009]. For instance, an increase of winter NAO multidecadal variability has been detected since 1850 [Wanner et al., 2001], while Paris's winter precipitation has increased by $24 \mathrm{~mm} /$ century since the 17 th century [Slonosky, 2002]. In addition, although NAO patterns remain dominant, at least since 1850, a nonnegligible fraction of variance accounted for by the EOFs (up to $22 \%$ ) on the multidecadal and interdecadal scales could be explained by different patterns than NAO. Indeed, the SLP patterns of multidecadal and interdecadal anomalies display a NE-SW dipole of anomaly centers, which could excite the SCAND and EA patterns at least for the interdecadal scale. In other words, it may correspond to an excitation of meridional circulations associated with blocking and Atlantic ridge patterns and/or, after a longer time lag, a southeastward shift of zonal circulations of the NAO pattern.

[44] Nonetheless, as proposed by Parker et al. [2007], the combined influence of the AMO and the NAO can be the source of regional climatic "surprises." Such interactions between the Atlantic Ocean and the NAO at the decadal time scale have already been examined in several studies [e.g., Schelsinger and Ramankutty, 1994; Higuchi et al., 1999; Rodwell et al., 1999; Enfield et al., 2001; Czaja and Frankignoul, 2002; Kushnir et al., 2002] but, in general, remain poorly understood. Hence, future research would need to be conducted on the investigation and identification of co-oscillations between atmospheric and oceanic variability, as well as on the characterization of multidecadal and interdecadal processes involved in the relationships between the North Atlantic and regional climates. Yet sensitivity experiments would be also necessary to delineate the respective contributions of natural variability and climate change, which will be essential for meeting the challenges of decadal predictions.

[45] Acknowledgments. The authors would like to thank the Upper Normandy regional research federation FED 4116 SCALE for financial support. The authors are also grateful to Dr Victoria Slonosky for her helpful friendly review of the manuscript.

\section{References}

Alexander, L. V., and P. D. Jones (2001), Updated precipitation series for the U.K. and discussion of recent extremes, Atmos. Sci. Lett., 1, 142-150, doi:10.1006/asle.2001.0025.

Allan, R., and T. Ansell (2006), A new globally complete monthly historical gridded mean sea level pressure data set (HadSLP2): 1850-2004, J. Clim., 19, 5816-5842, doi:10.1175/JCLI3937.1.

Barnston, A. G., and R. E. Livezey (1987), Classification, seasonality and persistence of low-frequency atmospheric circulation patterns, Mon. Weather Rev., 115, 1083-1126.

Cassou, C., L. Terray, and C. Deser (2004), North Atlantic winter climate regimes: spatial asymmetry, stationarity with time and oceanic forcing, J. Clim., 17, 1055-1068, doi:10.1175/1520-0442(2004)017.

Christensen, J. H., et al. (2007), Regional climate projections, in Climate Change 2007: The Physical Sciences Basis. Contribution of Working Group I to the Fourth Assessment Report of the Intergovernmental Panel on Climate Change, edited by S. Solomon, D. Qin, M. Manning, Z. Chen, M. Marquis, K. B. Averyt, M. Tignor, and H. L. Miller, 847-940, Cambridge Univ. Press, Cambridge.

Cleveland, W. S., and S. J. Devlin (1988), Locally weighted regression: an approach to regression analysis by local fitting, J. Am. Stat. Assoc., 83, 596-610. 
Cook, E. R., R. D. D’Arrigo, and K. R. Briffa (1998), The North Atlantic Oscillation and its expression in circum-Atlantic tree-ring chronologies from the North America and Europe, Holocene, 8, 9-17.

Czaja, A., and C. Frankignoul (2002), Observed impact of Atlantic SST anomalies on the North Atlantic Oscillation, J. Clim., 15, 606-623, doi:10.1175/1520-0442(2002)015<0606:OIOASA > 2.0.CO;2.

Delworth, T. L., S. Manabe, and R. J. Stouffer (1997), Multidecadal climate variability in Greenland Sea and surrounding regions: a coupled model simulation, Geophys. Res. Lett., 24, 1993-2011.

Enfield, D., A. M. Mesta-Nuñez, and P. Trimble (2001), The Atlantic multidecadal oscillation and its relation to rainfall and river flows in the continental US, Geophys. Res. Lett., 28, 2077-2080.

Folland, C. K., J. Knight, H. W. Linderholm, D. Fereday, S. Ineson, and J. W. Hurrell (2009) The summer North Atlantic Oscillation: past, present, and future, J. Clim., 22, 1082-1103, doi:10.1175/2008JCLI2459.1.

Gamiz-Fortis, S. R., D. Pozo-Vasquez, R. M. Trigo, and Y. Castro-Diez (2008), Quantifying the predictability of winter river flow in Iberia. Part I: Interannual predictability, J. Clim., 21, 2484-2502, doi:10.1175/ 2007JCLI1774.1.

Goldenberg, S. B., C. W. Landsea, M. Mestas-Nuñez, and W. M. Gray (2001), The recent increase in Atlantic hurricane activity: Causes and implications, Science, 293, 474-479.

Gray, S. T., L. J. Graumlich, J. L. Betancourt, and G. T. Pederson (2004), A tree-ring based reconstruction of the Atlantic Multidecadal Oscillation since 1567, Geophys. Res. Lett., 31, L12205, doi:10.1029/ 2004GL019932.

Higuchi, K., J. Huang, and A. Shabbar (1999), A wavelet characterization of the North Atlantic Ocean variation and its relationship to the North Atlantic sea surface temperature, Int. J. Climatol., 19, 1119-1129.

Hilmer, M., and T. Jung (2000), Evidence for a recent change in the link between the North Atlantic Oscillation and Artic sea ice export, Geophys. Res. Lett., 27, 989-992.

Holman, I. P., M. Rivas-Casado, J. P. Bloomfield, and J. J. Gurdak (2011), Identifying non-stationary groundwater level response to North Atlantic ocean-atmosphere teleconnection patterns using wavelet coherence, Hydro. J., 19, 1269-1278, doi:10.1111/j.1469-7610.2011.02419.x.

Hurrell, J. W. (1995), Decadal trends in the North Atlantic Oscillation: Regional temperatures and precipitation, Science, 269, 676-679.

Hurrell, J. W., and C. Deser (2009), North Atlantic climate variability: the role of the North Atlantic Oscillation, J. Mar. Syst., 78, 28-41, doi:10.1016/j.jmarsys.2008.11.026.

Jansen, E., et al. (2007), Palaeoclimate, in Climate Change 2007: The Physical Sciences Basis. Contribution of Working Group I to the Fourth Assessment Report of the Intergovernmental Panel on Climate Change, edited by S. Solomon, D. Qin, M. Manning, Z. Chen, M. Marquis, K. B. Averyt, M. Tignor, and H. L. Miller, 433-497, Cambridge Univ. Press, Cambridge.

Jung, T., M. Hilmer, E. Ruprecht, S. Kleppek, S. Gulev, and O. Zolina (2003), Characteristics of the recent eastward shift of interannual NAO variability, J. Clim., 16, 3371-3382, doi:10.1175/1520-0442(2003) $016<3371$ :COTRES $>2.0 . \mathrm{CO} ; 2$

Kendall, M. G. (1948), Rank Correlation Methods, 160pp., Charles Griffin, London, U. K..

Kingston, D. G., G. R. Mc Gregor, D. M. Hannah, and D. M. Lawler (2006), River flow teleconnections across the northern North Atlantic region, Geophys. Res. Lett., 33, L14705, doi:10.1029/ 2006GL026574.

Kingston, D. G., G. R. Mc Gregor, D. M. Hannah, and D. M. Lawler (2007), Large-scale climatic controls on New England River Flow, J. Hydrometeorol., 8, 367-379, doi:10.1175/JHM584.1.

Knight, J. R., C. K. Folland, and A. A. Scaife (2006), Climate impacts of the Atlantic Multidecadal Oscillation, Geophys. Res. Lett., 33, L17706, doi:10.1029/2006GL026242.

Kodera, K., and Y. Kuroda (2005), A possible mechanism of solar modulation of the spatial structure of the North Atlantic Oscillation, J. Geophys. Res., 101, D02111, doi:10.1029/2004JD005258.

Kushnir, Y., W. A. Robinson, I. Bladé, N. M. Hall, S. Peng, and R. Sutton (2002), Atmospheric GCM response to extratropical SST anomalies: Synthesis and evaluation, J. Clim., 15, 2233-2256, doi:10.1175/1520-0442 (2002)015<2233:AGRTES > 2.0.CO;2.

Labat, D. (2005), Recent advances in wavelet analyses: Part I. A review of concepts, J. Hydrol., 314, 275-288, doi:10.1016/j. jhydrol.2005.04.003.

Luterbacher, J., C. Schmutz, D. Gyalistras, E. Xoplaki, and H. Wanner, (1999), Reconstruction of monthly NAO and EU indices back to AD 1675, Geophys. Res. Lett., 26, 2745-2748.

Luterbacher, J., E. Xoplaki, D. Dietrich, R. Rickly, J. Jacobeit, C. Beck, D. Gyalistras, C. Schmutz, and H. Wanner (2002), Reconstruction of sea level pressure fields over the eastern north Atlantic and Europe back to 1500, Clim. Dyn., 18, 545-561, doi:10.1007/s00382-001-0196-6.
Luterbacher, J., D. Dietrich, E. Xoplaki, M. Grosjean, and H. Wanner (2004), European seasonal and annual temperature variability, trends and extremes since 1500, Science, 303, 1499-1503, doi:10.1126/ science. 1093877.

Manley, G. (1974), Central England temperature: Monthly means 1659 to 1973, Q. J. R. Meteorol. Soc., 100, 389-405.

Mann, H. B. (1945), Non-parametric test against trend, Econometrica, 13, 245-259.

Mann, M. E., J. Park, and R. S. Bradley (1995), Global interdecadal and century-scale climate oscillations during the past five centuries, Nature, $378,266-270$

Maraun, D. (2006), What can we learn from climate data? Methods for fluctuation time/scale and phase analysis, PhD thesis, Univ. of Postdam, Potsdam, Germany.

Massei, N., A. Durand, J. Deloffre, J. P. Dupont, D. Valdes, and B. Laignel (2007), Investigating possible links between the North Atlantic Oscillation and rainfall variability in northwestern France over the past 35 years, J. Geophys. Res., 112, D09121, doi:10.1029/2005JD07000.

Massei, N., B. Laignel, J. Deloffre, J. Mesquita, A. Motelay, R. Lafite, and A. Durand (2010), Long-term hydrological changes of the Seine River flow (France) and their relations to the North Atlantic Oscillation over the period 1950-2008, Int. J. Climatol., 30, 2146-2154, doi:10.1002/ joc. 2022 .

Mitchell, T. D., and P. D. Jones (2005), An improved method of constructing database of monthly climate observations and associated high-resolution grids, Int. J. Climatol., 25, 693-712, doi:10.1002/ joc. 1181 .

Mokhov, I. I., A. V. Eliseev, D. Handorf, V. K. Petukhov, K. Dethloff, A. Weisheimer, and D. V. Khvrost'yanov (2000), North Atlantic Oscillation: Diagnosis and simulation of decadal variability and its long-period evolution, Izv., Atmos. Oceanic Phys., 36, 555-565.

Osborn T. J. (2004), Simulating the winter North Atlantic Oscillation: The roles of internal variability and greenhouse gas forcing, Clim. Dyn., 22, 605-623, doi:10.1007/s00382-004-0405-1.

Parker, D., C. K. Folland, A. A. Scaife, J. R. Knight, A. Colman, P. Baines, and D. Dong (2007), Decadal to multidecadal variability and the climate change background, J. Geophys. Res., 112, D18115, doi:10.1029/2007JD008411.

Parry, M. L. (2000), Assessment of the Potential Effects and Adaptations for Climate Change in Europe: The Europe ACACIA Project, Jackson Environment Institute, Univ. of East Anglia, Norwich, U. K.

Pauling, A., J. Luterbacher, C. Casty, and H. Wanner (2006), 500 years of gridded high resolution precipitations over Europe and the connection to large-scale circulation, Clim. Dyn., 26, 387-405, doi:10.1007/s00382005-0090-8

Peterson, T. C., and R. S. Vose (1997), An overview of the Global Historical Climatology Network temperature database, Bull. Am. Meteorol. Soc., 78, 2837-2849.

Preisendorfer, R. W. (1988), Principal Component Analysis in Meteorology and Oceanography, Elsevier, Amsterdam.

Rodwell, M. J., D. P. Rowell, and C. K. Folland (1999), Oceanic forcing of wintertime North Atlantic Oscillation and European climate, Nature, 398, 320-323.

Rousseau, D. (2009), Les températures mensuelles en région parisienne de 1676 à 2008, Meteorologie, 67, 43-55, doi:10.4267/2042/30038.

Schelsinger, M. E., and N. Ramankutty (1994), An oscillation in the global climate system of period 65-75 years, Science, 367, 723-726.

Schmutz, C., J. Luterbacher, D. Gyalistras, E. Xoplaki, and H. Wanner (2000), Can we trust proxy-based NAO index reconstructions?, Geophys. Res. Lett., 27, 1135-1138.

Slimani, S., N. Massei, J. Mesquita, D. Valdès, M. Fournier, B. Laignel, and J. P. Dupont (2009), Combined climatic and geological forcings on the spatio-temporal variability of piezometric levels in the chalk aquifer of Upper Normandy (France) at pluridecennal scale, Hydrogeol. J., 17, 1823-1832, doi:10.1007/s10040-009-0488-1.

Slonosky, V. C. (2002), Wet winters, dry summers? Three centuries of precipitation data from Paris, Geophys. Res. Lett., 2919, 1895, doi:10.1029/ 2001GL014302.

Slonosky, V. C., P. D. Jones, and T. D. Davies (2000), Variability of the surface atmospheric circulation over Europe, 1774-1995, Int. J. Climatol., 20, 1875-1897.

Sutton, R. T., and B. Dong (2012), Atlantic Ocean influence on a shift in European climate in the 1990s, Nat. Geosci., 5, 788-792, doi:10.1038/ ngeo1595117.

Sutton, R. T., and D. L. R. Hodson (2005), Atlantic Ocean forcing of North American and European summer climate, Science, 309, 115-118, doi:10.1126/science. 1109496

Tabony, R. C. (1980), A set of homogeneous European rainfall series, Met. O.13 Branch Memorandum No. 104, Meteorological Office, Bracknell. Tabony, R. C. (1981), A principal component and spectral analysis of European rainfall, J. Climatol., 1, 283-294. 


\section{DIEPPOIS ET AL.: N ATLANTIC AND NW EUROPEAN CLIMATE}

Thompson R. (1999), A time-series analysis of the changing seasonality of precipitation in the British Isles and neighbouring areas, J. Hydrol., $224,169-183$

Thompson, R., and R. M. Clark (2008), Is spring starting earlier?, Holocene, 18, 95-104, doi:10.1177/0959683607085599.

Torrence, C., and G. P. Compo (1998), A practical guide to wavelet analysis, Bull. Am. Meteorol. Soc., 79, 61-78.

Torrence, C., and P. Webster (1999), Interdecadal changes in the ENSOMonsoon system, J. Clim., 12, 2679-2690.

van der Schrier, G., and S. L. Weber (2009), The Gulf Stream and Atlantic sea-surface temperatures in $\mathrm{AD}$ 1790-1825, Int. J. Climatol., 30, 1747-1763, doi:10.1002/joc. 2027. van Loon, H., J. Brown, and R. F. Milliff (2012), Trends in sunspots and North Atlantic sea level pressure, J. Geophys. Res., 17, D07106, doi:10.1029/2012JD017502.

Wanner, H., S. Brönnimann, C. Casty, D. Gyalistras, J. Luterbacher, C. Schmutz, D. B. Stephenson, and E. Xoplaki (2001), North Atlantic Oscillation-Concepts and studies, Surv. Geophys., 22, 321-382.

Zhang, R., T. L. Delworth, and I. M. Held (2007), Can the Atlantic drive the observed multidecadal variability in the Northern Hemisphere mean temperature? Geophys. Res. Lett., 34, L02709, doi:10.1029/2006GL028683. 